\begin{tabular}{l|c|c}
\hline \hline $2002,47-51$ & ETHICS IN SCIENCE AND ENVIRONMENTAL POLITICS & Published September 26 \\
\hline
\end{tabular}

\title{
The challenges of energy - response to Moody-Stuart
}

\author{
John Houghton* \\ John Ray Initiative, Francis Close Hall, University of Gloucestershire, Swindon Road, Cheltenham GL 50 4AZ, United Kingdom
}

\begin{abstract}
Sir Mark has lucidly addressed the growing demand for accessible energy throughout the world, the need for basic provision of energy to one third of the world's population and the conflicts that arise between the ways in which energy is supplied and used and the constraints of sustainability. It is, of course, the innovation, creativity and activity of industry that will provide solutions to the problems we face. It is therefore appropriate and helpful to hear from one of the leaders of the energy industry. The vision he presents is one of a vibrant, innovative, market-driven industry operating within a regulatory framework that gives the maximum flexibility for creative solutions. The greatest challenges faced by the world energy sector are concerned with environmental sustainability. Because the emissions of greenhouse gases such as carbon dioxide spread rapidly around the globe, sustainability has to be considered on a global basis and global solutions are required. International agreements concerning action, for instance the Framework Convention on Climate Change (FCCC), need to be based on sound science and on 4 widely accepted principles, namely the Precautionary Principle, the Polluter Pays Principle and the Principles of Sustainable Development and Equity. The challenge to the FCCC is to devise mechanisms and arrangements that will bring about substantial reductions in greenhouse gas concentrations in the atmosphere and that also satisfy these principles. A recent Energy Review from the Policy Innovation Unit of the UK Government's Cabinet Office has considered in detail how a sustainable energy strategy can be developed. Finally, reasons are given for optimism that, given the necessary commitment by the world community, a sustainable energy strategy for the world can be developed and realised during the 21st century.
\end{abstract}

Resale or republication not permitted without written consent of the publisher

\section{THE NEED FOR INTERNATIONAL REGULATION}

I would like, first, to say more about the nature of the regulatory framework and the basis on which it has to be constructed. Because the emissions of greenhouse gases such as carbon dioxide spread rapidly around the global atmosphere, the resulting changes of climate are global in extent affecting all nations. Global pollution demands global solutions. The top level of regulatory agreements therefore must be international. Other areas where science is strongly involved with policy such as that of genetic modification (GM) also require that regulation be international, although

*E-mail: john.houghton@jri.org.uk for different reasons. In the case of GM where there is strong competition between industrial companies, if regulations differ between different countries, industries in some countries will be at a competitive disadvantage.

The first example of an international regulatory environment agreement was the Montreal Protocol set up in the late 1980s to address the problem of ozone depletion due to emissions of chlorine-containing chemicals such as the CFCs. That agreement has been successful in substantially reducing the production of the relevant chemicals and their release into the atmosphere. Their concentration in the stratosphere (the region of the atmosphere containing ozone) is now falling and the loss of atmospheric ozone is beginning to recover, although full recovery will take at least a century. 


\section{The necessary basis of scientific assessment}

At the basis of any international agreement must be acceptance of the reality of the threat. Careful and thorough scientific assessment, internationally organised, is therefore essential. This is particularly important when dealing with a subject such as the climate. Climate is and always has been very variable, globally, regionally and on all time scales. Climate extremes, floods, droughts and storms are some of the worst disasters human communities experience. The challenge to climate scientists is to distinguish between natural variability and trends and identify changes that are likely to be due to human activities (especially the burning of fossil fuels) and their likely impacts. They then have had to explain to a public, which is partly sceptical and partly gullible, in accurate honest terms what is known about climate change and what the aspects where uncertainties are large are. The Intergovernmental Panel on Climate change (IPCC) was set up in 1988 to address these issues. It has been successful in bringing together a large proportion of the world community of scientists involved in the climate change issue (both natural scientists and socioeconomic experts) to debate and articulate comprehensive assessments of the basic science, the likely impacts and the adaptation and mitigation options (Houghton 2002). The latest IPCC assessment was published in 2001. It is in 3 volumes, each of about 1000 pages and with many thousands of references to the scientific literature together with technical and policymakers' summaries (IPCC 2001). It confirms that, because of human activities, the climate is changing at a rate greater than has occurred for at least 10000 years, a rate to which it will be difficult to adapt for many humans and many ecosystems. There will be many impacts on human communities, a few positive in some places but mostly negative. The largest impacts will occur because of the rise of sea level as the ocean warms and because of the more intense hydrological cycle that will occur in a warmer world and that will lead to more frequent and intense floods and droughts in many places. Adaptation will be required to meet the level of climate change that will almost certainly occur. Action to mitigate climate change will be largely through achieving substantial reductions in the emissions of the main 'greenhouse gases' namely carbon dioxide and methane.

\section{The Framework Convention on Climate Change (FCCC)}

The IPCC's first report in 1990 with its clear statements about the likely impact of human activities on the climate informed discussions at the Earth Summit at Rio de Janeiro in 1992 that led to agreement by all the participating nations to the Framework Convention on Climate Change (FCCC). President Bush signed for the USA. I quote some extracts from the FCCC to illustrate its content (Houghton 1997). First, the Objective of the Convention is in Article 2, as follows:

The ultimate objective of this Convention and any related legal instruments that the Conference of the Parties may adopt is to achieve...stabilization of greenhouse gas concentrations in the atmosphere at a level that would prevent dangerous anthropogenic interference with the climate system. Such a level should be achieved within a time frame sufficient to allow ecosystems to adapt naturally to climate change, to ensure that food production is not threatened and to enable economic development to proceed in a sustainable manner.

Article 3 deals with principles and includes agreement that the Parties

take precautionary measures to anticipate, prevent or minimize the causes of climate change and mitigate its adverse effects. Where there are threats of serious or irreversible damage, lack of full scientific certainty should not be used as a reason for postponing such measures, taking into account that policies and measures to deal with climate change should be cost-effective so as to ensure global benefits at the lowest possible cost.

Article 4 is concerned with Commitments. In this article, each of the signatories to the Convention agrees

to adopt national policies and take corresponding measures on the mitigation of climate change, by limiting the anthropogenic emissions of greenhouse gases and protecting and enhancing its greenhouse sinks and reservoirs. These policies and measures will demonstrate that developed countries are taking the lead in modifying longerterm trends in anthropogenic emissions consistent with the objective of the Convention, recognizing that the return by the end of the present decade to earlier levels of anthropogenic emissions of carbon dioxide and other greenhouse gases... would contribute to such modification...

Although the FCCC talks of action, binding actions awaited the formulation of Protocols to the FCCC. The first binding actions were hammered out in the Kyoto Protocol which requires developed nations to reduce their greenhouse gas emissions by 2010 on average by about $5 \%$ below 1990 levels. Although the USA has announced that it is not ratifying the Protocol, it has been hoped that it will be ratified by sufficient countries for it to come into force before the World Summit on Sustainable Development in August-September 2002 in Johannesberg; however, it is possible that this may not occur before 2003.

\section{FOUR PRINCIPLES OF INTERNATIONAL AGREEMENTS}

Four widely accepted principles govern the necessary international agreements on Climate Change or 
on any similar global environmental issues, namely:

- the Precautionary Principle which states that the existence of uncertainty should not preclude the taking of appropriate action;

- the Principle of Sustainable Development that requires that a balance be struck between the needs of the environment and other needs of human communities;

- the Polluter Pays Principle that implies the imposition of measures such as carbon taxes or carbon capping and trading arrangements;

- the Principle of Equity, both international and intergenerational.

These principles are recognized within the formulation of the FCCC. The first is stated in Article 3. The second is spelt out in the Objective of the Convention. The third is basic to the measures and mechanisms of the Kyoto Protocol. The fourth is implied in Article 4, where developed countries are required to take the lead.

The application of the 4 principles is raising a great deal of debate. The first two require judgements to be made between competing claims or constraints as to which claims or constraints are genuine and which are put forward in defence of vested interests. The measures and arrangements proposed under the third principle can inevitably give rise to undesirable distortions or side effects that may seriously affect particular nations, communities or groups. The fourth is particularly difficult to apply. The need for carbon-based energy differs enormously between different communities or countries and inequities already abound in human societies for all sorts of reasons.

There is one radical proposal for action that is being widely discussed and which seeks to address the 4 principles in a straightforward manner. That is the 'Contraction and Convergence' proposal put forward by the Global Commons Institute (www.gci.org.uk) and endorsed by the recent report on Energy by the Royal Commission on Environmental Pollution (2000; www.rcep.org.uk). It begins with the requirement of the objective of the FCCC to stabilize carbon dioxide concentrations at a level that meets the requirements of Principles 1 and 2; a level of 450 ppm is suggested - the lowest level that has any practical possibility of being achieved. Even at this level, the rate of expected climate change will be larger than it has been for at least 10000 years and severe impacts are likely in many locations. A level of $550 \mathrm{ppm}$ is often quoted as more practicable, although still far from easy, and the impacts would be more severe. Either of these concentration targets imply immediate reductions in the rate of growth of global carbon dioxide emissions and reductions to below current values by around the middle of the 21 st century. That is the 'contraction' part of the proposal.
To meet the Principle of Equity they propose the simplest possible solution namely that carbon dioxide emissions should be allocated equally per capita to all countries from some date such as 2030 and that there should be 'convergence' to that situation during the decades in between. That is a very radical proposal. In 2030, depending on the world population at that date, the allocation per capita would be somewhat less than 1 tonne carbon per person per year compared with current usage of about $5.5 \mathrm{t}$ in the USA, 2.5 in the UK, 0.7 in China, 0.3 in India and 1.0 averaged for the world. The final part of the proposal is that, after the allocations have been made, trading should take place between nations, consistent with Principle 3. This would result in a substantial transfer of funds from the developed to the developing world where, at least in principle, it could be used to finance the development of sustainable energy sources.

A feature of the Contraction and Convergence proposal is that, because of its comparative simplicity, it can concentrate the minds of decision makers on the scale of the problem and its challenge.

\section{THE UK PIU REPORT}

I now turn to the situation in the UK and comment in particular on the recent Energy Review put out by the Policy Innovation Unit (PIU) of the Cabinet Office (PIU 2002; www.cabinet-office.gov. uk/innovation). It is a review that addresses long-term energy needs and policy. It bases much of its view of the future on the target for carbon dioxide emissions put forward in the RCEP's Energy Report of a reduction of $60 \%$ by 2050. This is based on a stabilization level of $550 \mathrm{ppm}^{1}$ and the recognition that additional reductions will be necessary in developed countries to allow some growth in developing countries seeking to industrialize. The Review contains many positive general statements about what is needed. Let me give some examples:

From the Prime Minister's foreword:
Alongside low prices and secure supplies, climate change has become a central aspect of energy policy. Achieving global emission reductions will need major technological innovation, and I am convinced that the UK would benefit from being ahead of the game in moving to clean and low carbon technologies and in sharply improving our performance on energy efficiency.

\footnotetext{
${ }^{1}$ The Report does not make it clear whether this is a figure for $\mathrm{CO}_{2}$ alone or for 'equivalent $\mathrm{CO}_{2}$ ', which would take into account the growth of gases other than $\mathrm{CO}_{2}$ i in the latter case the corresponding figure for $\mathrm{CO}_{2}$ alone would be less than $500 \mathrm{ppm}$
} 
From the executive summary, key points:

\begin{abstract}
...New challenges require new policies. The policy framework should address all 3 objectives of sustainable development-economic, environmental and social - as well as energy security. Climate change objectives must largely be achieved through the energy system. Where energy policy decisions involve trade-offs between environmental and other objectives, then environmental objectives will tend to take preference ... Key policy principles should be: to create and to keep open options to meet future challenges; to avoid locking prematurely into options that may prove costly; and to maintain flexibility in the face of uncertainty. Increasingly policy towards energy security, technological innovation and climate change will be pursued in a global arena, as part of an international effort.
\end{abstract}

In the key points of its Executive Summary, the Review also details some of the necessary elements of the UK's future energy strategy and some of the targets that the strategy should set:

Keeping options open will require support and encouragement for innovation in a broad range of energy technologies. The focus of UK policy should be to establish new sources of energy which are, or can be, low cost and low carbon.

Later on the Review acknowledges that funding for research and development (R \& D) in the UK has fallen to levels that are inadequate and emphasizes that central to this process of innovation will be a stronger R \& D base.

The immediate priorities of energy policy are likely to be most cost-effectively served by promoting energy efficiency and expanding the role of renewables. However, the options of new investment in nuclear power and in clean coal (through carbon sequestration) need to be kept open, and practical measures taken to do this.

\section{The Review also proposes that:}

The Government should initiate a national public debate about sustainable energy, including the roles of nuclear power and renewables ... Institutional barriers to renewable and combined heat and power investments should be addressed urgently ... The Government should use economic instruments to bring home the cost of carbon emissions to all energy users and enable UK firms to participate in international carbon trading. Achieving deep cuts in carbon would require action well beyond the electricity sector where cuts have been concentrated in recent years.

Later on the Review emphasizes the scale of the challenge by pointing out that very large reductions will be necessary in the use of fossil fuels as the main means of powering future vehicles. The Review also urges that:

Within the next 5 years, the Government should move towards a clear rationale for the balance of policy instruments - taxes, permits and regulation - to create powerful incentives for long-term carbon reduction and take immediate action to assist innovation, to create new options and also to manage risk

... Step changes in energy efficiency and vehicle efficiency are needed, with new targets for both. In the domestic sector, the Government should target a $20 \%$ improvement in energy efficiency by 2010 and a further $20 \%$ in the following decade. The target for the proportion of electricity generated from renewable sources should be increased to $20 \%$ by 2020 .

Particular institutional changes that the Review proposes to facilitate the new energy strategy are to 'create a new cross-cutting Sustainable Energy Policy Unit to draw together all dimensions of energy policy in the UK' and 'to bring together the three interlinked themes in this review - energy policy, climate change policy and transport policy - in one department of state.' In addition changes to the planning system are also required.

Concern is often expressed about the cost to the economy of taking radical action of the kind that is outlined in the Review. The Review has carried out a careful study of the cost to the economy in aggregate terms to get a $60 \%$ reduction in carbon emissions by 2050 . They report as follows (paragraph 7.115):

The Inter-Departmental Analysts' Group (IAG) spent some time analysing this issue and, though there is much uncertainty so far into the future, some bounds can be put on to the likely cost. There are various ways of expressing this cost. The simplest is probably in terms of the loss of economic growth. On the assumption that economic growth will continue at the historic annual rate $2.25 \%$, GDP would triple over 50 years. IAG estimates suggest that 0.02 percentage points might be lost from the growth rate - equivalent to a loss of only around 6 months' GDP growth over 50 years. In other words, we might lose only $1 \%$ of all the economic growth we expect over the next half a century. In return, the benefits would be a major contribution to the international effort to mitigate climate change. While achieving a $60 \%$ cut in carbon emissions by 2050 would be challenging, it could be done while still achieving economic growth rates of around $2.25 \%$.

Finally with respect to the Review is the question of commitment on the part of government and its clarity of purpose. That this is required is spelt out clearly in the last paragraph of the Executive Summary, as follows:

The nation must not be lulled into inaction by the focus of much of the expert debate on long timescales and on energy systems in a future which will belong mainly to our grandchildren: the time for action is now and all players in the energy system have a role to play. Given that there is considerable inertia in the system, and that the low carbon technologies are not part of the conventional energy system, a change of direction will be difficult to achieve. It will require clarity of purpose in all parts of Government.

Earlier, however, a damper is put on this seemingly unequivocal statement of necessary commitment in 
one of the key points in the Executive Summary that reads as follows:

There is a strong likelihood that the UK will need to make very large carbon emission reductions over the next century. However, it would make no sense for the UK to incur large abatement costs, harming its international competitiveness, if other countries were not doing the same.

In the light of the relatively low estimates of likely cost to the economy made in the PIU Review and in other studies (IPCC 2001), it is hard to see why it seemed necessary to introduce such a strong cautionary tone. Further, one of the key points in the Review's summary states that where energy policy decisions involve trade-offs between environmental and other objectives including economic ones, then environmental objectives will tend to take preference. The UK has often expressed pride in its leadership role in the world in this and other issues. Such leadership is badly needed, in particular towards the USA where strong vested interests are lobbying intensively for inaction. The UK with its tradition of high quality, accurate and responsible science should unequivocally present a clear strategy for long-term action that other countries can be encouraged to follow and that can also provide the framework and stimulus required for industry to deliver what is required. As individuals also we all need clear guidance as to what each of us can do to make our consumption patterns more sustainable and to reduce the contribution to carbon dioxide emissions for which we are each responsible.

\section{CONCLUDING REMARKS}

I am often asked whether there is any hope at all that the problem of climate change can be solved and sus- tainable energy production and consumption achieved. Is not the problem too large and too difficult for humans to solve? I reply that I am optimistic for 3 reasons. Firstly, I have experienced the remarkable degree of consensus achieved by the world scientific community regarding the broad picture of what is likely regarding future climate change and the options for adapting to it and mitigating it - this despite the substantial degree of uncertainty in much of the detail. Secondly, although much technical development is required, the technologies required to provide for substantial mitigation of climate change are available. Thirdly, I believe that humans, created in the image of God, are able to respond to the challenge and are not on their own in doing so. As others in this conference have been reminding us (for example Dean-Drummond 2002) God is deeply involved in his creation and committed to it. Wisdom that begins with 'the fear of the Lord' (Proverbs 9 v. 10) is offered as the operating principle that we can all employ as we try to move towards a more sustainable world.

\section{LITERATURE CITED}

Deane-Drummond C (2002) this volume, p 65-74

Houghton, JT (1997) Global warming: the complete briefing. Cambridge University Press, Cambridge

Houghton JT (2002) Global environmental change. In: Hester RE, Harrison RM (eds) Issues in environmental science and technology No. 17. Royal Society of Chemistry, London

IPCC (2001) Climate change 2001. Cambridge University Press, Cambridge (also available on the Internet at www.ipcc.ch.)

IPCC (2001) Climate change 2001: mitigation. Cambridge University Press, Cambridge 